\title{
Corrigendum: RNAseq Profiling of Leukocyte Populations in Zebrafish Larvae Reveals a cxcl11 Chemokine Gene as a Marker of Macrophage Polarization During Mycobacterial Infection
}

\author{
Julien Rougeot ${ }^{1}$, Vincenzo Torraca ${ }^{1}$, Ania Zakrzewska ${ }^{1}$, Zakia Kanwal ${ }^{1}$, Hans J. Jansen ${ }^{2}$, \\ Frida Sommer ${ }^{1}$, Herman P. Spaink ${ }^{1}$ and Annemarie H. Meijer ${ }^{1 *}$ \\ ${ }^{1}$ Institute of Biology Leiden, Leiden University, Leiden, Netherlands, ${ }^{2}$ ZF-screens B. V., Leiden, Netherlands
}

Keywords: innate immunity, zebrafish, RNAseq, macrophage, mycobacteria, neutrophil, lymphoid progenitor cells

OPEN ACCESS

Edited and reviewed by: Tiehui Wang,

University of Aberdeen,

United Kingdom

*Correspondence:

Annemarie H. Meijer a.h.meijer@biology.leidenuniv.nl

Specialty section: This article was submitted to

Comparative Immunology,

a section of the journal

Frontiers in Immunology

Received: 03 October 2019 Accepted: 06 November 2019 Published: 02 December 2019

Citation:

Rougeot J, Torraca V, Zakrzewska A, Kanwal Z, Jansen HJ, Sommer F, Spaink HP and Meijer AH (2019) Corrigendum: RNAseq Profiling of Leukocyte Populations in Zebrafish

Larvae Reveals a cxcl11 Chemokine Gene as a Marker of Macrophage Polarization During Mycobacterial Infection. Front. Immunol. 10:2720. doi: 10.3389/fimmu.2019.02720

\section{A Corrigendum on}

RNAseq Profiling of Leukocyte Populations in Zebrafish Larvae Reveals a cxcl11 Chemokine Gene as a Marker of Macrophage Polarization During Mycobacterial Infection by Rougeot, J., Torraca, V., Zakrzewska, A., Kanwal, Z., Jansen, H. J., Sommer, F., et al. (2019). Front. Immunol. 10:832. doi: 10.3389/fimmu.2019.00832

In the original article, there was an omission. The "Data Availability Statement" section was absent in the edited manuscript.

The Data Availability Statement has now been added to the published article:

"The sequencing data for infected samples have been submitted to the NCBI Gene Expression Omnibus (GEO; http://www.ncbi.nlm.nih.gov/geo/) under accession number GSE68920. The sequencing data for uninfected samples were made previously available under accession number GSE78954. The sequencing data for human macrophages are available under the accession number GSE36952."

In the "Materials and Methods" section, "RNA Isolation, Illumina Sequencing, and Real time PCRs" subsection, the sequences of the primers $c c r 5(\mathrm{ccr} 12 \mathrm{~b} .2) \mathrm{Fw}$ and $\mathrm{ccr} 5 \mathrm{Rv}$ were erroneous. The correct sequences are $c c r 5(c c r 12 b .2) F w$ : GGCTTCCAACATCATCTTCACCCTCAC; $c c r 5 R v$ : CTATCATCCGAGTGCGCATGATGG.

The authors apologize for this error and state that this does not change the scientific conclusions of the article in any way. The original article has been updated.

Copyright (๐ 2019 Rougeot, Torraca, Zakrzewska, Kanwal, Jansen, Sommer, Spaink and Meijer. This is an open-access article distributed under the terms of the Creative Commons Attribution License (CC BY). The use, distribution or reproduction in other forums is permitted, provided the original author(s) and the copyright owner(s) are credited and that the original publication in this journal is cited, in accordance with accepted academic practice. No use, distribution or reproduction is permitted which does not comply with these terms. 